\title{
Ecological principles affecting community structure and secondary production by zooplankton in marine and freshwater environments ${ }^{1}$
}

\author{
John T. Lehman \\ Department of Biology, Natural Science Building, University of Michigan, Ann Arbor 48109
}

\begin{abstract}
The production dynamics of zooplankton have becn studied within two alternative conceptual frameworks. Some workers have emphasized the species composition of communities and the reproductive success of individual species, whereas others have studied the flow of nutrients and energy among ecosystem components. The reduced phylogenetic diversity of lake plankton compared with marine systems has favored the development of species-based community ecology by limnologists. Theories that promote size structure as the salient community feature have bcen pioneered in marine systems and sometimes adopted for freshwater work. Empirical trends in physiological processes with organism size permit some rates to be estimated from size structure alone. With few exceptions, however, coefficients derived from log-transformed regression equations have been applied uncritically in models, and little regard has been given to the large estimation errors involved. Metrics that are based on differences between physiological processes, rather than absolute rates of individual processes, are important ecologically. Threshold food concentration is an example: it measures the relative performance of food acquisition ability compared to acquisition and maintenance costs. These intcgrative properties do not vary strictly with organism size and they illustrate the fact that biological entities can develop many alternative solutions to the problems they face. Such results imply that whenever resource exploitation influences community composition, organism-specific adaptations will prove more predictive than size structure.
\end{abstract}

Comparative reviews of marine and freshwater environments share some of the same problems and present some of the same opportunities as do comparisons of aquatic and terrestrial systems. Little overlap exists in species composition among these environments, and the biological communities are enriched with representatives of differing physiology, life history, and markedly different phylogenetic descent. Regardless of their surroundings, the organisms nonethcless facc common basic challenges to survival and reproduction. They must acquire resources, evade or frustrate predators, and propagate viable descendants. These challenges forge the common ecological principles that are most amenable to comparative studies.

Comparisons among aquatic environments are particularly instructive, because the organisms face common constraints imposed by the presence of a bounding fluid that is not too different in density from their body tissues. Many members of the plank-

${ }^{1}$ Supported by Office of Naval Rescarch contract N00014-84K-0671 and National Science Foundation grant OCE 84-15970. ton can complete their life histories and never contact a boundary or surface. Investments in structural tissue to maintain body form against the force of gravity have consequently received little selection pressure, and this probably accounts for the poor fossil history of some groups. The unifying similarities among marine and freshwater habitats stem from the physical properties of water, especially in regard to buoyancy and viscosity. Implications of the milieu for physiology are more system-specific. The osmotic challenges of life in freshwaters discourage invasion of the habitat by many marine invertebrates, although to claim that as the sole barrier to colonization is to ignore other ecological challenges. Freshwater faunas are additionally shaped by requirements for dispersal mechanisms and resting stages, to a far greater extent than are marine plankton.

Secondary production has been the subject of many competent reviews within the last decade for both marine (Conover 1979; Harrison 1980; Williams 1984) and freshwater (Wetzel 1983; Downing and Rigler 1984) environments. Because the IBP handbook on methods for estimating secondary 
production has been recently revised and reissued (Downing and Rigler 1984), many of the technical aspects of analysis require no elaboration here. Other workers have described methods for calculating secondary production and have tabulated representative values. Rather than tread well-worn paths, this review will consider some of the existing themes in marine and freshwater investigations and try to seek fruitful directions and common grounds for progress in zooplankton production biology and ecology.

Ecological investigations of secondary production in zooplankton communities exhibit striking differences of approach. This is because the process called secondary production can be regarded fundamentally either as a conduit for the flow of mass and energy across trophic levels or as the mechanism by which individual populations maintain their existence. Both of these views have broad applicability to aquatic environments. In even more general terms, it is possible to classify most investigations of zooplankton into three broad categories: taxonomy and zoogeography, mass flux and energetics, and population dynamics and community structure.

These categories encompass both freshwater and marine examples, although some approaches are more richly represented in one discipline. The first category is the oldest and best defined. The sources of knowledge and the drives for activity in this field are the same ones that promote all investigations of systematics and systems of classification. These motives require studying biological diversity in the broadest sense, inquiring about patterns of speciation, and opening avenues of paleontological inference. Topics like cosmopolitanism vs. regionalism in faunal distributions belong among these inquires (e.g. Green 1972; Pejler 1977; Frey 1982), although the distribution patterns of species can sometimes be interpreted with respect to the other two categories. This is particularly true when clements of one regional fauna invade or become introduced into another. Under those conditions, attention is drawn to matters like susceptibility to invasion and co- herence of alternative food webs. Such phenomena lead naturally to the second and third categories, which are the principal subjects of this paper.

Secondary production is defined here broadly as the collective term for the myriad processes by which animals sustain and propagate themselves. These processes involve in part the mechanics of gathering food and cxtracting nutrition from it and in part the algorithms for life history patterns and survival strategies. Narrower definitions, such as growth of somatic and reproductive tissue, are alternative ways to define secondary production, but they constrain comparisons among species or communities. A focus solely on growth or growth efficiency (net mass gain per unit mass ingested), for instance, lends well to energetic approaches but poorly to population dynamic studies. There is an unfortunate tendency to cast the approaches of system energetics and population dynamics into conflict, as though ecosystem studies embody "hiclistic" perspectives, but organismbased studies remain "reductionistic" (Rigler 1975). In fact, these topics are neither opposite ends of a spectrum nor opposing alternative viewpoints. Both are based on fundamental and sound principles, but they do not derive from each other. Neither approach surpasses or encompasses the other. Mass flux and energy flow obey the first law of thermodynamics. Inquiries about these subjects require basic input-output analyses balanced on carbon mass or nitrogen mass or else accountings of the fluxes of chemically bound potential energy between subsets of the system.

Community and population studies are tied ultimately to natural selection theory. Energy flux is of lesser interest than individual fitness in this framework, because survival and persistence are the virtues that define successful species, whether or not they dominate community biomass and material flux. The contrast is between properties of genetic entities and properties of the conservation laws. Recent reviews of secondary production reveal a strong desire to find rules of general validity and broad predictive strength. Special attention has been paid to 
relationships based on individual body size or biomass (e.g. Conover 1979), which hold the promise of predicting metabolic rates and production from simple measurements (Huntley and Boyd 1984; Huntlcy 1985). Extensive tabulations are now available of physiological processes like ingestion, respiration, and motility with respect to individual size (e.g. Peters 1983). This activity has encouraged the drive toward models of community and ecosystem dynamics that treat the size structure of organisms present in a system rather than the phyletic composition of the system (e.g. Steele and Frost 1977; Conover and Huntley 1980; Silvert and Platt 1980; Carpenter and Kitchell 1984; Huntley and Boyd 1984; Sprules and Knoechel 1984; Knoechel and Holtby 1986).

What often goes unnoticed is that the quantities that are of ecological interest in terms of their survival value are not the absolute magnitudes of individual rates but, rather, the differences between rates. Organisms are influenced by not just one allometric relationship but by many. For example, net assimilation, respiration, minimum generation times, and many other physiological or demographic attributes exhibit positive trends with body size. Some of these allometries conflict. Large-bodied species can swim faster to escape enemies or capture prey, but they are more conspicuous to visual hunting predators. Conceivably, there are environmental conditions under which the net balances betwecn rates of assimilation and respiration differ among similarly sized taxa, even among those at the same trophic level. Among species for which the balance is positive, somatic growth and reproduction are possible; for others survival depends on their strategies for coping with deprivation. Some may alter their rates of metabolism or experience enzyme inductions (Landry and Hassett 1985; Mayzaud and Mayzaud 1985), and others may invoke life history solutions. The array of potential responses is diverse bccause individual species have evolved unique solutions to their problems. Species diversity itself is the evidence that many alternate solutions are possible when organisms are faced with conflicting allometric con- straints. Before examining this proposition in quantitative terms, it is worthwhile to review the general scheme of plankton diversity in oceans and freshwaters.

\section{Species richness}

Hutchinson's (1961) "paradox of the plankton" defines the challenge to explanation presented by the species diversity of plankton communities. A single vertical haul in the epi- and mesopelagic regions of the north central Pacific, for instance, nets more than 300 species of zooplankton (McGowan and Walker 1979). The plankton environment is the oldest habitat on earth and its denizens are the products of ceaseless natural experiments. The phylogenetic diversity of marine zooplankton represents almost the full range of the marine invertebrate fauna (Table 1), particularly in coastal regions where the larvae of benthic animals join the plankton seasonally. Faced with such a bewildering array of potential species interactions, it is little wonder that investigations of marine plankton often emphasize mass and energy flow rather than food web structure and ecological interactions between species. Compounding this problem of diversity is the fact that an accurate census of marine plankton is notoriously difficult (Tranter 1976), to the extent that some workers believe that time series data which are essential to population studies are nearly impossible to gather reliably (Steele 1978).

Freshwater plankton communities exhibit reduced species richness compared to marine systems. The water column of offshore Lake Michigan, for instance, contains no more than 15 crustacean species and 10 species of rotifers in readily detectable abundance at any one moment. The freshwater zooplankton fauna is also greatly restricted in phylogenetic breadth compared with marine waters (Table 1). Many important invertebrate groups (e.g. Echinodermata, Ctenophora, Chaetognatha) have failed to colonize freshwater habitats, but in some cases their roles have been assumed by the successful radiation of aquatic insects, particularly the Diptera, in lakes and streams. For example, Chaoborus, the 
Table 1. Representative zooplankton taxa present in either marine or freshwaters. Common -*; present, but rare or represented by few species -+ ; absent or extremely rare -0 .

\begin{tabular}{|c|c|c|}
\hline & Marine & $\begin{array}{l}\text { Fresh- } \\
\text { water }\end{array}$ \\
\hline \multicolumn{3}{|l|}{ Protista } \\
\hline Mastigophora & $*$ & $*$ \\
\hline Sarcodinea & $*$ & $*$ \\
\hline Foraminifera & $*$ & 0 \\
\hline Radiolaria & $*$ & 0 \\
\hline Ciliata & $*$ & $*$ \\
\hline Tintinnina & $*$ & 0 \\
\hline \multicolumn{3}{|l|}{ Metazoa } \\
\hline \multicolumn{3}{|l|}{ Cnidaria } \\
\hline Hydrozoa & $*$ & + \\
\hline Scyphozoa & * & 0 \\
\hline Ctenophora & $*$ & 0 \\
\hline Rotatoria & + & $*$ \\
\hline Mollusca & & $+t$ \\
\hline \multicolumn{3}{|l|}{ Gastropoda } \\
\hline Heteropoda & $*$ & 0 \\
\hline Pteropoda & $*$ & 0 \\
\hline \multicolumn{3}{|l|}{ Annelida } \\
\hline Polychaeta & $*$ & 0 \\
\hline \multicolumn{3}{|l|}{ Arthropoda } \\
\hline \multicolumn{3}{|l|}{ Crustacea } \\
\hline Branchiopoda & + & $*$ \\
\hline Cladocera & $t$ & $*$ \\
\hline Copepoda & $*$ & $*$ \\
\hline Calanoida & $*$ & $*$ \\
\hline Cyclopoida & $*$ & $*$ \\
\hline \multicolumn{3}{|l|}{ Malacostraca } \\
\hline Mysidacea & $*$ & $*$ \\
\hline Amphipoda & $*$ & + \\
\hline Euphausiacea & $*$ & 0 \\
\hline Decapoda & $*$ & 0 \\
\hline Insecta & 0 & $*$ \\
\hline Chaetognatha & $*$ & 0 \\
\hline \multicolumn{3}{|l|}{ Chordata } \\
\hline Appendiculata (Larvacea) & $*$ & 0 \\
\hline \multicolumn{3}{|l|}{ Thaliacea } \\
\hline Cyclomyaria (Doliolida) & $*$ & 0 \\
\hline Desmomyaria (Salpida) & $*$ & 0 \\
\hline $\begin{array}{c}\text { Diverse invertebrate larvae, par- } \\
\text { ticularly in coastal regions }\end{array}$ & * & 0 \\
\hline
\end{tabular}

† In Old World lakes, larvac of Dreissensia (Bivalvia) can be common seasonally.

phantom midge larva, enjoys a planktivorous existence not unlike that of Sagitta, the arrowworm. Both are ambush predators that detect their prey by mechanoreception. Despite such complementary niche exploitations, freshwater environments remain species-poor by comparison with the oceans.

Much of this difference may be owed to the greater depth, antiquity, and continuity of oceanic plankton environments. The role of age alone is problematic, because even the relict lakes Tanganyika and Malawi have only modest zooplankton faunas despite a rich endemism of vertebrates. In Lake Tanganyika, the genus Microcyclops radiated into several endemic species (Hutchinson 1967), although most of them may not be truly planktonic (Brooks 1950). Otherwise the open-water zooplankton is species-poor, with only one common species of Calanoida and no planktonic Cladocera (Beadle 1981). The crustacean zooplankton of Lake Malawi consists of only six common species (Twombly 1983). Although both of these lakes have mean depths that rival some ocean regions, they are permanently stratified and only the wind-driven surface layers are oxygenated. The relict lakes Baikal and Ohrid, on the other hand, have oxygen-rich hypolimnia, but nonetheless exhibit only a slight degree of endemism among the zooplankton. In Baikal, however, there is a rich endemic amphipod fauna, some of which are pelagic. These lakes do not rival the species richness of marine zooplankton. Only six or seven species of rotifers inhabit the open waters of Lake Baikal, one of which is endemic (Kozhov 1963), and only two calanoid species are common, neither of which is endemic (Brooks 1950).

A further contrast between marine and freshwater zooplankton communities involves the compositional features of the plankton with latitude. In general, the diversity of marine plankton decreases from low latitudes to high ones (Ryther 1969; Valentine and Ayala 1978). Tropical and subtropical ocean waters exhibit rich diversity of zooplankton, whereas arctic and antarctic waters tend to be dominated by either lipid-accumulating copepods or euphausiids. The latitudinal trend in species richness of freshwaters is the opposite. Tropical lakes have abbreviated zooplankton faunas compared with temperate locales (Fernando $1980 a, b)$. Tropical lakes are depauperate in large-bodied species of copepods and Cladocera; limnetic rotifers (Monogononta) are likewise poorly represented.

This trend toward simplified zooplankton communities in tropical lakes is contrary not only to latitudinal trends in marine plankton but to those of terrestrial plant and 
animal communities as well. Several reasons can be advanced for the apparent anomaly, but if the arguments are to be plausible, they must take into account the effects on all of the faunal elements. Fernando $(1980 b)$ argued, for instance, that tropical lake plankton exhibit many similarities with littoral or pond faunas, and this he attributed to a paucity of truly limnetic habitats at low latitudes worldwide. The plankton faunas of Tanganyika and Malawi, as well as those of other African Rift Valley lakes and lake districts, share the overall trend of low species richness, however, and it seems unlikely that the reason should be simply that these regions were never colonized by many taxa. Most limnetic zooplankton taxa have broad regional or cosmopolitan distributions, or perhaps the species complexes are so closely allied morphologically that they appear cosmopolitan (Frey 1982). Calanoid copepods appear to have distinct morphological species that are restricted to regional distributions (Hutchinson 1967). The common feature of freshwater zooplankton species which promotes their broad dispersal capabilities and simultaneously allows them to endure inhospitable growth conditions is that most major taxa possess means to form resting stages. This is a near universal characteristic that distinguishes the organisms from oceanic species in regard to life history attributes. Because coastal and estuarine zooplankton also can form resting eggs (Heinle 1981), some marine copepods obviously are capable of expressing this characteristic, but it is equally obvious that the trait must be selected against rapidly in pelagic oceanic regimes. A dominant mode of arrested development found among oceanic copepods is the overwintering behavior of copepodid stages in deep, cold waters (Heinle 1981). Although feeding may stop and growth is slowed, the animals produce no spccialized structures to resist hostile environments.

The most reasonable lines of inquiry about the species richness of different habitats may involve the physiological and ecological conditions faced by the plankton. First, there may be direct temperature effects on demographic properties like fecundity, egg development, or age at primiparity that favor some taxa over others. Patalas and Salki (1984) argued that Cladocera can outperform calanoid copepods during summer months because warm temperatures promote their rapid development. Fernando (1980a) claimed, in contrast, that large Cladocera, and Daphnia in particular, are discouraged by the warm temperatures of the tropics. Fecundities of Daphnia species decline at temperatures above $15^{\circ} \mathrm{C}$ (LeSeur 1960; Orcutt and Porter 1983), and Lynch (1977) has proposed that ecologically optimal body sizes decline with temperature. Fecundity variation with temperature must be interpreted with caution, however, for, as Orcutt and Porter (1983) have shown, accelerated development times can allow population growth rates to increase at elevated temperatures despite lower fecundities.

Beyond these direct physiological influences, the biological interactions of predation and resource competition may also differ latitudinally. Visual-directed predators, typically fish, are an undeniable force in zooplankton communities (Hrbáček et al. 1961; Hrbáček 1962; Brooks and Dodson 1965, Galbraith 1967; Wells 1970; Hall et al. 1976; Lynch 1979; O'Brien 1979; Zaret 1980). Some of the seminal work on the role of plankton visibility in selective zooplanktivory by fish was conducted with tropical species (Zaret 1969, 1972, 1975; Zaret and Suffern 1976). Large-bodied zooplankton are typically the most conspicuous and hence the more likely to fall prey to foraging vertebrate planktivores. In temperate lakcs, the plankton can evidently rely on the survival strategy of diapause to avoid not only hostile physical conditions but calamitous episodes of planktivory as well (Strickler and Twombly 1975; Nilssen 1978, 1980; Hairston and Munns 1984). This is because the mortality risks are seasonal and periodic. In tropical lakes diapause is a doubtful strategy for avoiding mortality because planktivory is not relaxed seasonally, nor do growth conditions differ remarkably from time to time. Even in Lake Malawi, which sits astride a subtropical convergence of air masses and thus experiences seasonality of atmospheric conditions, the zooplankton fauna exhibits some seasonality (Twombly 1983), but, 
compared with temperate locales, the animals change only modestly in abundances. Under such circumstances, an animal gains nothing by diapausing because conditions never improve.

A case can be made that the difference between species richness of marine and freshwater zooplankton faunas derives from the necessity of diapause, anabiosis, or other resting mechanisms as a condition for persistent successful radiation in freshwaters. All freshwater environments are ephemeral. Resting stages are exploited both as dispersal mechanisms and as means of risk avoidance. The constraint of this requirement has probably discouraged from widespread success all but a few families of copepods, notably the Diaptomidae, Centropagidae, Temoridae, and Cyclopidae. It has also encouraged the rise of groups with characteristically freshwater distributions, notably the Branchiopoda and Rotifera. Although marine representatives of these groups are well known, it is likely that they have radiated secondarily from freshwater ancestors. Glacial relict faunas, like freshwater Mysidacea, are instructive exceptions. These animals had distributions limited by southward morainal margins of continental glaciers (Hutchinson 1967), at least until the advent of artificial introductions. The conflicting demands of resting stages for exploitation of freshwater habitats and their diminished value in tropical lakes may account for some of the peculiarities of zooplankton community composition. The direct mechanism for reduced species numbers in the tropics may be intense planktivory, which would account for the paucity of large-bodied zooplankton in tropical lakes (Gliwicz 1985). But not only large crustacean zooplankton are at issue. Rotifers are relatively inconspicuous to vertebrate planktivores, and yet their faunas are not diversified in the tropics. A general explanation of the mechanisms may rely on the economics of metabolism, a point which is explored below.

\section{Conflicting allometries: The individual solution}

As argued above, diversity of biological species represents an extant set of unique solutions to the conflicting demands faced by organisms in nature. At first glance, it might appear that the scope of potential responses is strongly constrained. This is the assertion that buoys efforts to use size structure to characterize communities and to investigate their dynamics. Size is an observable feature of organisms, and the empirical variation of physiological processes with individual size is indisputable. Across several orders of magnitude in body size, for example, the rates of ingestion by zooplankton can be calculated to within tenfold by reference to individual size and littlc else (Peters and Downing 1984; Knoechel and Holtby 1986). If interspecies differences were useful only to distinguish residual uncertainty, the differences could plausibly be ignored in many applications. Before embracing this conclusion, however, it is wise to examine the ecological consequences of combining individual physiological processes.

For animals of given size, the empirical rates of physiological processes like respiration or ingestion are approximately lognormally distributed. This is evident from the fact that plots of these rates are routinely subjected to logarithmic transformations in part to linearize relationships and in part to stabilize the variance (Fig. 1). Unlike the normal curve, which arises from the addition of a large number of small independent random variables, the lognormal can be derived by combination of many sources of error through the multiplication of proportionate errors (Koch 1966; May 1981). The interrelationship of these two distributions is easily understood by reference to the explicit probability density function, $\operatorname{pdf}(x)$, for a lognormally distributed random variable, $x$ (Johnson and Leone 1964):

$$
\begin{aligned}
\operatorname{pdf}(x)= & 1 /\left[\sigma(2 \pi)^{1 / 2}\right] \cdot 1 / x \\
& \cdot \exp \left\{-[\ln (x)-U]^{2} / 2 \sigma^{2}\right\} \\
& (x>0)
\end{aligned}
$$

where $\ln (x)$ has a normal distribution with mean $U$ and standard deviation $\sigma$. Thus, for the lognormal distribution, the mean $(\mu)$ and variance $\left(S^{2}\right)$ are

$$
\mu=\exp \left(U+\sigma^{2} / 2\right)
$$


and

$$
S^{2}=\mu^{2}\left[\exp \left(\sigma^{2}\right)-1\right]
$$

One practical significance of these relationships is that mean expected rates cannot be calculated from log-log regression equations by directly computing the antilogarithms of regression coefficients; the expected values must be corrected by Eq. 2, just as Bird and Prairie (1985) advised. This fact, long known by statisticians (Finney 1941), has been disregarded in most applications (Sprugel 1983). More importantly, the process of computing differences between lognormal distributions is not a trivial exercise. Unlike the case with normal distributions, for which sums and differences remain normally distributed, the difference between two lognormal distributions is neither normal nor lognormal. Nonetheless, these calculations are of considerable ecological interest because it is the net accounting of gains over losses by which populations prosper or decline. They are of interest as well to an investigation of the overall utility of empirical correlation models in ecological contexts. Individual physiological processes are well represented by empirical regression equations, and extant variability may fall within acceptable limits, but what matters most at the individual level is not the absolute magnitude of ingestion rate, or the absolute magnitude of respiration rate, but rather the difference between the two.

In order to subtract one distribution from another it is appropriate to perform a difference convolution:

$$
g(z)=\int_{-\infty}^{+\infty} f 1(z+x) \cdot f 2(x) \mathrm{d} x
$$

where $g(z)$ is the convolved (difference) distribution and $f 1$ and $f 2$ are the known distributions. The formula permits calculation of the probability density at which any value $z$ results from all of the possible combinations of $f 1$ and $f 2$ which yield that difference. A graphic illustration of the procedure is shown in Fig. 2. The example is for the difference between ingestion rates and basal respiration rates of poikilotherms. Empiri-
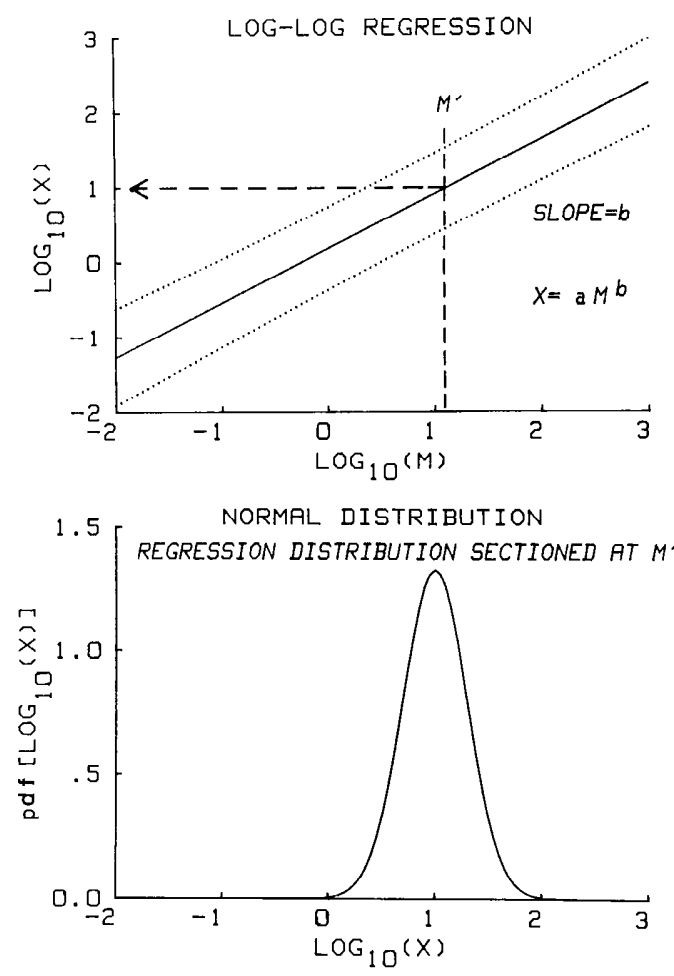

Fig. 1. Illustration of the use of double-logarithmic transformations in ecological studies. Above-logarithms of organism mass $(M)$ are plotted against logarithms of a process rate $(X)$, such as ingestion or respiration. A regression line of slope $b$ is identificd (solid line), which characterizes the mean trend of the distribution outlined ( $95 \%$ confidence region: dotted lines). Below-a cross section through the log-transformed data at $M^{\prime}$ (dashed line) has mean $=1$ and a symmetrical, normally distributed probability density function (pdf).

cal correlations have established that elevations of the log-transformed regression equations differ by fourfold (Peters 1983, table 7.1), and that this ratio does not vary with organism size (see also Romanovsky 1984). It seems that ingestion procceds four times faster than basal respiration in all of these animals, on average. Whether this is fact depends on the patterns of variability and the propagated uncertainty. The plots of the assembled data (Farlow 1976) or residual variances (Robinson et al. 1983) suggest a tenfold range of variation at any one body size for each process. Accordingly, the logarithmically transformed normal distributions were assigned standard deviations 

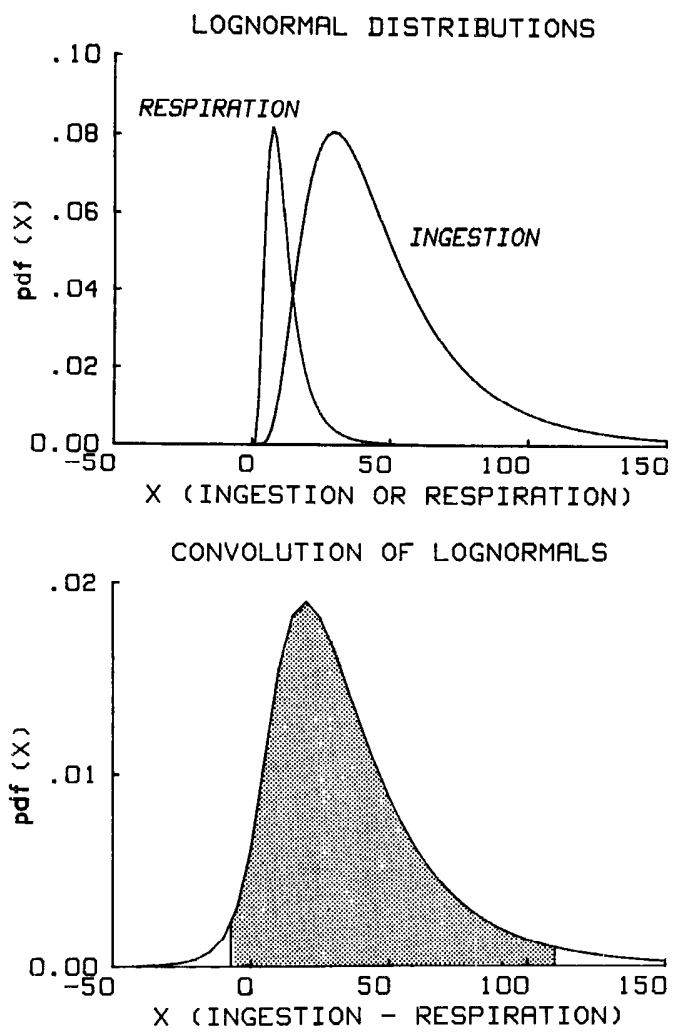

Fig. 2. Above-lognormal distributions constructed from data for poikilotherms (Peters 1983). The probability density function (pdf) for ingestion is drawn from fourfold vertical exaggeration for clarity. Both of these lognormal distributions would have identical normal shapes if plotted on a logarithmic scale. The $\log _{10}$-transformed distributions would have mean $=1$ $(\mathrm{SD}=0.25)$ for respiration and mean $=4(\mathrm{SD}=0.25)$ for ingestion. The lognormal distributions have mean $=$ $11.8(\mathrm{SD}=7.4)$ for respiration and mean $=47.2$ $(\mathrm{SD}=29.6)$ for ingestion. Below-difference convolution of two lognormal distributions. The explicit numerical algorithm for the calculation was

$$
\begin{aligned}
g\left(z_{j}\right)= & \sum_{i=0}^{n}\left[f 1\left(z_{j}+x_{i+1}\right)+f 1\left(z_{j}+x_{i}\right)\right] \\
& \cdot\left[f 2\left(x_{i+1}\right)+f 2\left(x_{i}\right)\right]\left(x_{i+1}-x_{i}\right) / 4
\end{aligned}
$$

where $x_{i}=i \cdot 1.05^{i-1}, n=100$, and $z_{j}=5 \cdot j-100$. The shaded region represents $95 \%$ of the area of the pdf; $2.5 \%$ of the area is present in each tail.

of 0.25 ( $\log _{10}$ units), so that the $95 \%$ confidence regions of the distributions ( $\pm 2 \mathrm{SD}$ ) would extend over one order of magnitude. Then the two lognormal distributions $(f 1$ : ingestion; $f 2$ : respiration) were generated and convolved by numerical trapezoidal in- tegration (Fig. 2). The results show broad variation in the expected values that result from subtracting the two lognormal distributions. Far from the conclusion that ingestion rates exceed respiration by fourfold, the central $95 \%$ of expected net values lie in a range that includes zero!

The available physiological data therefore do not imply that organisms are narrowly constrained. Even though individual processes vary with body size in a manner that suggests there are rules transcending individual adaptation, organisms do not behave like machines assembled from random assortments of metabolic rates. The random combinations that lead to negative values in Fig. 2, for instance, are obviously not evolutionarily stable. Values that are calculated as the difference between the means of two lognormal distributions carry very little predictive power. There obviously is selective pressure for secure positive somatic growth rates, and this implies that ingestion, respiration, and growth must be correlated (e.g. Condrey 1982; Condrey and Fuller 1985). The exercise suggests that net results of physiological processes are not reliably predictable from surveys of average component rates. Unlike primary production, which can sensibly be regarded in terms of either "gross" or "net" components, secondary production is exclusively a "net" process. As such, it makes sense to measure net processes like somatic growth directly (e.g. Mullin and Brooks 1970; Harris and Paffenhöfer 1976; Lynch et al. 1986) or to compare the environmental conditions that permit different species (or organisms of different body size) to perform at standard reference levels. These levels could be those of maximum somatic growth rate, incipient reproduction, minimum generation time, or something else. The easiest level to define is that of threshold maintenance, or the environmental conditions at which production is zero, and so that is used here for reference.

Several methods have been used to identify threshold food concentrations for zooplankton species (Table 2). These are the concentrations of food at which rates of assimilation and respiration are in balance, so that no biomass accrual or reproduction is 
Table 2. Studies in which threshold food concentrations were determined for representative zooplankton taxa. The techniques and organisms used in the studies are indicated.

\begin{tabular}{ll}
\hline \hline \multicolumn{1}{c}{ Methods for estimating food thresholds } & \multicolumn{1}{c}{ References } \\
\hline Net intrinsic population growth rate, $r$ (rotifers) & Stemberger and Gilbert 1985 \\
Difference between assimilation and metabolic losses (Daphnia) & Lampert 1977 \\
Direct weight gain (Calanus, Pseudocalanus, Daphnia, Eudiapto- & Vidal 180; Muck and Lampert 1984; \\
mus, Arctodiatomus) & Piyasiri 1985 \\
Egg production rate (Acartia, Diaptomus) & Durbin et al. 1983; Williamson et al. \\
& 1985 \\
\hline
\end{tabular}

possible. Threshold concentrations are particularly valuable in the context of resourcebased competition, because they help to predict whether one species may exclude another by exploitative means. For instance, if one organism can continue to gain weight at food concentrations at which others starve, and if its population grows numerous enough to control food abundance, it may be able to suppress resources to levels that are too low to sustain the others. Romanovsky $(1984,1985)$ argued that differences in threshold levels among freshwater cladocerans determine their distribution and success in lakes of different trophic condition. The principle is very similar to the concept of $R^{*}$ (Tilman 1980,1982), which is the critical resource level necessary for the persistence of a species in an environment. Tilman introduced $R^{*}$ for algal populations, in which all individuals of a species are regarded to have the same requirements. Among zooplankton the situation is more complex, because adults and juveniles of the same species may have different threshold food concentrations necessary for survival. This point is particularly evident in Fig. 3, where threshold food concentrations are shown to increase modestly with body size for Calanus pacificus and for Daphnia pulex. Lampert and Schober (1980) have pointed out that actual ecological requirements for species persistence in nature should be even higher than these physiological thresholds imply. Populations in nature must sustain some net growth in order to balance mortalities. The specics which prosper at any given moment are those for which prevailing resource levels permit population growth in excess of mortalities. The relevant "ecological thresholds" are more challenging to identify, but physio- logical thresholds nonetheless provide convenient reference values by which to begin comparing different species.

Threshold food concentrations assembled from a varicty of sources are plotted in Fig. 4, together with the body masses of the zooplankton used in the determinations. Although trends are certainly evident within single taxa, the trends are not sustained across all groups. Among zooplankton species which vary in individual body mass by 10,000-fold, threshold food levels vary by 100 -fold, independent of body size. What can be said from the scant data is that rotifers require relatively concentrated food and that small calanoid copepods can survive on very dilute rations. A trend expected on theoretical grounds (Gerritsen and Kou 1985) toward smaller threshold requirements at large body size is not endorsed by the data. The other generalization, evident in Fig. 3, is that threshold food levels increase with water temperature. In warm waters, both Daphnia and Calanus require high food concentrations merely to stay alive.

This observation leads to an alternative hypothesis about the species composition of tropical freshwater zooplankton communities. Food acquisition abilities do not always keep pace with metabolic costs as temperatures rise. This problem may be worse for large-bodied crustacean zooplankton than for small ones because the burden of metabolism is borne by the entire body mass, whereas food can be acquired only at the appendages. Larger animals may face the classic surface-to-volume dilemma. Thus, for metabolic reasons we might expect large Cladocera and large copepods to be excluded from all but the richest food environments in warm tropical regions. By 

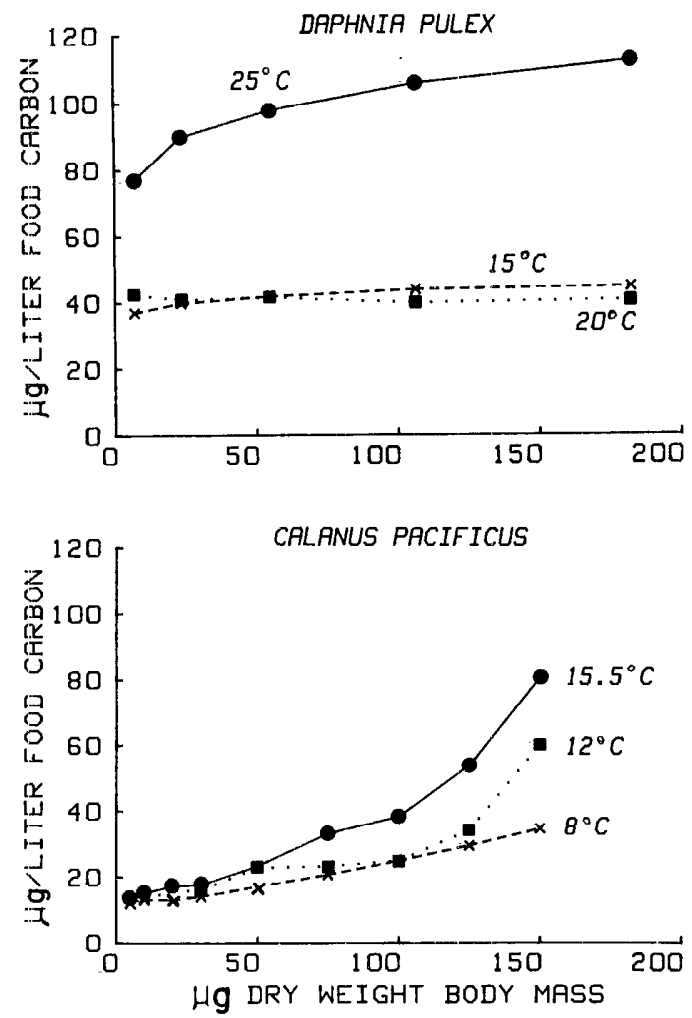

Fig. 3. Threshold food concentrations expressed as $\mu \mathrm{g} \mathrm{C}$ liter $^{-1}$ for $D$. pulex and $C$. pacificus. Values for Daphnia were calculated from data presented by Lampert 1977; Calanus data are from Vidal 1980.

similar reasoning, it makes sense that large crustacean zooplankton dominate oceanic regions at high latitudes, but that microzooplankton comprise respectable fractions of the tropical fauna (Vinogradov 1981). The fact that this trend parallels the expected pattern in predation intensity merely means that the forces may act in concert (Gliwicz 1985).

Rotifers appear to be a special case in that the small animals require high threshold food concentrations. This is potentially related to their unique method of food capture by means of ciliary corona. Schiemer (1985) has suggested that mechanics of food acquisition are a dominant determinant of food thresholds. Lampert and Muck (1985), on the other hand, suggest that the differences between Eudiaptomus and Daphnia are more related to the greater efficiency of maintenance metabolism in the copepod.

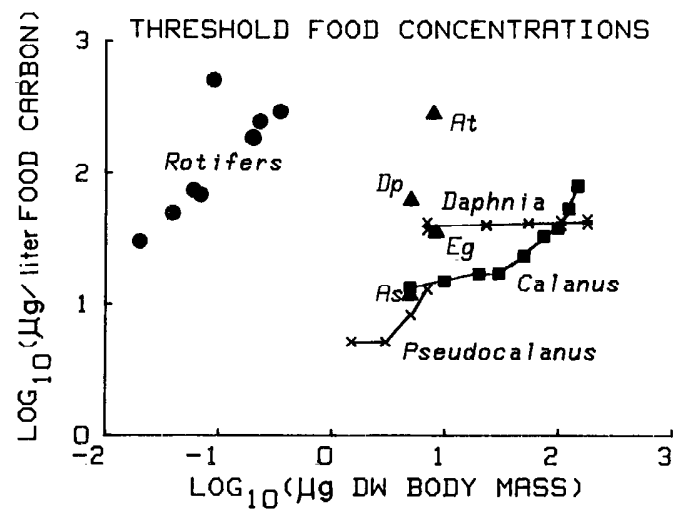

Fig. 4. Threshold food concentrations and body masses for zooplankton, $15^{\circ}-20^{\circ} \mathrm{C}$. Data are from studics referenced in Table 2. At-Acartia tonsa; DpDiaptomus pallidus; As-Arctodiaptomus spinosus.

Regardless of whether one of these explanations applies to the rotifers, it is clear that their life suits their rapid episodes of parthenogenetic reproduction punctuated by formation of resting eggs. Such a fugitive lifestyle may not be best suited for environments with reduced seasonality, as in the tropics. As Romanovsky (1984, 1985) pointed out, there is a high degree of individuality in the ways that even closely allied taxa craft their life histories and to the consequences this can have for their competitive abilities.

\section{Analogous niches}

The functional similarities of planktivory practiced by freshwater Chaoborus and by marine Chaetognatha were described earlier. Such analogies between distant phylogenetic representatives are common. For example, although Cladocera can be found in marine waters, the group is basically confined to freshwater. The ecological role of the Cladocera seems to be filled in ocean waters at least in part by the pelagic thaliaceans. These salps and doliolids possess some of the feeding and life history characteristics that are strongly reminiscent of the cladoceran lifestyle. The animals arc prodigious filter feeders (Alldredge 1984), evidently showing much less selectivity than copepods, a trait shared by feeders like Daphnia (Meise et al. 1985). Moreover, both groups share the ability to reproduce asex- 
ually and to expand their populations rapidly under ideal growth conditions. And, like some Daphnia whose thoracic appendages become clogged with algal filaments (Infante and Abella 1985), at least one pelagic salp finds its filtering apparatus clogged with algae when abundances rise too high (Harbison et al. 1986).

The analogies are obviously imperfect because only a Daphnia can do what a Daphnia does and because within both Cladocera and Thaliacea there is remarkable radiation, diversity, and improvisation. The salps, for instance, are not subject to the same surface-to-volume dilemma described above for crustacean zooplankton. Their Urochordate type of pump-filter apparatus permits efficient food capture, and large colonial animals are successful in warm seas. The comparisons show nonetheless that strong phylogenetic differences do not preclude functional convergences and that the classes of solutions crafted by biological species to their ecological problems in both oceans and lakes overlap considerably.

Biomass turnover, detritus, and grazer effects

The difficulties of assigning secure and meaningful values to the rates of secondary production by zooplankton communities have been recognized by most reviewers (e.g. Conover 1979; Wetzel 1983). The point of such inquiries is to learn how much of the energy, carbon, or nutrient mass that is potentially available will be transferred efficiently into organisms that are themselves harvested by higher level consumers, as opposed to passing into a detritus-based food web. The question is made doubly difficult at present because even the rates of primary production are under debate (e.g. Schulenberger and Reid 1981; Jenkins 1982; Laws et al. 1984). It is also becoming clear that detritus is not a dead-end repository for productivity. The strongest drives to investigate detritus-based food chains come from calculations showing that detritus is a major fuel for secondary productivity in many ecosystems (Mann 1988). Large fluxes of material, however, do not intrinsically have a major forcing role in life processes. Almost all phagotrophs survive by metaboliz- ing dead organic matter (although some of the food was alive when captured). The fundamental difference between harvesting detritus and living organisms, however, is uniquely biological. Living organisms have the capacity to evolve antipredator and other mechanisms, whereas there is little selective advantage to mechanisms that work only after death. Still awaiting answer is whether most of the detritus in aquatic systems arises from physiological death (senescence), predation (sensu latu), or disease.

Biomass turnover times (i.e. the reciprocal of $P / B$ ) reported for freshwater zooplankton vary from $1.7 \mathrm{~d}$ for rotifers to 162 d for arctic Diaptomidae (Wetzel 1983, table 16-12). Similarly, for marine zooplankton the minimum compiled turnover time is $1.3 \mathrm{~d}$ (Conover 1979, table 7), the rate reported for copepods in nearshore tropical water. Most computed turnover times are considerably longer, in the range of 5-10 d. Turnover times of the phytoplankton are regarded to be considerably shorter in most cases. Lewis (1974), for instance, found turnover times as short as $0.23 \mathrm{~d}$ based on published reports, and he discovered that the vast majority of turnover times available for lake phytoplankton communities averaged $<3 \mathrm{~d}$. This conclusion was drawn likewise by Sheldon et al. (1972) for marine communities, although their work preceded the studies of fast-growing gelatinous marine species. By comparison with the algae, the relatively modest turnover times reported for zooplankton encourage the conclusion that most metazoan zooplankton cannot regulate phytoplankton by virtue of superior growth rates. That zooplankton grazing is sufficient at times to balance phytoplankton production and to influence the species composition of the algae is widely accepted (Gliwicz 1975; Gamble 1978; Lynch and Shapiro 1981; Steele and Gamble 1982), although it is clear that mortalities are directed against algal species differentially and that for many species the pressures are minimal (Lehman and Sandgren 1985). For this reason, the concept of threshold food levels must take into account not only the quantity of phytoplankton available but also its availability to different types of grazers (e.g. Richman and Dodson 
1983) or possible feeding interferences (e.g. Infante and Abella 1985).

There is currently much interest in the role of food limitation among zooplankton communities, and evidence is mounting that competition for scarce food may be a fixture of both marine and freshwater communities (Lampert 1985). If resource competition does indeed play a major role in community organization, organism-specific adaptations will prove especially important for deciphering the patterns in nature.

\section{Microheterotrophs and their food webs}

The role of microheterotrophs (flagellates, ciliates, amoebae, and nauplii) in aquatic food webs has become a subject of considerable interest (Pomeroy 1979; Sorokin 1981). Few published figures for the secondary production of these organisms have been compiled, but their biomass turnover times are extremely rapid. Their quantitative significance to patterns of mass and energy flow depends, nonetheless, on their biomass representation in different ecosystems. By some estimates, they are capable of harvesting large fractions of daily primary production (Beers and Stewart 1971; Landry and Hassett 1982). Many of these small grazers are in fact only facultative phagotrophs. Some representatives of the dinoflagellates, chrysomonads, and cryptomonads possess both autotrophic and heterotrophic means of nutrition. Such duality of trophic position may prove to be widespread (Bird and Kalff 1986).

Patterns of microheterotroph species richness, geographical distribution, and comparisons among marine and freshwater ecosystems deserve more than the superficial attention they can be given here. The general paucity of metazoan freshwater zooplankton species compared to marine species will not likely extend to microheterotrophs, but the awesome diversity of Protista discourages the requisite comparisons in this report. It is evident, however, that even among the microheterotrophs, individual adaptations can lead to remarkable success. The offshore plankton of Lake Tanganyika, for example, is often dominated by a single species of Strombidium (Hecky and Kling 1981). The ciliate possesses symbiotic zoo- chlorellae, a feature that represents one solution to the ecological challenge of $\mathrm{mi}$ croheterotrophy. The inherent difficulty of calculating secondary production for the creature is obvious, although judging from its persistence and success, the net balance of metabolic gains and losses is extremely favorable.

\section{Conclusions}

The major difference between marine and freshwater zooplankton communities is the reduced diversity found in lakes. Not only is the phyletic representation lower among the freshwater fauna (Table 1), but the specics richness exhibited by groups like copepods is far lower in freshwater habitats. Both osmotic challenges and the requirement for mechanisms of resting stage formation have likely hindered many marine taxa from invading the habitat. Characteristic freshwater taxa like branchiopods and rotifers have not speciated sufficiently to compensate in numbers for the missing marine species. By any accounting, lake zooplankton is species-poor when compared to ocean communities. The differences may be charged to the greater antiquity, depth, and continuity of the oceans. In ancient lakes, however, the zooplankton communities are not enriched, and endemic species are rare among the true limnetic zooplankton, even when rich endemism of the benthic fauna is evident. The fundamental reason for the difference remains unresolved.

For pragmatic reasons, the study of mass and energy flow has dominated the study of marine zooplankton. Population studies are made difficult by patchiness, uncertain boundaries, and the myriad of interactions that are possible among hundreds of species. Instead, there is a drive to characterize zooplankton communities in terms of size structure, and to infer dynamics from physiological correlates of organism size. To date, the size-based approaches have been extraordinarily facile. The models have emphasized the mean fit of regression lines to data, as though deviations from the line represent error rather than unique adaptation. With few exceptions, coefficients have been applied improperly by ignoring the biases implicit in the statistical transformations. 
The differences between lognormally distributed variables like ingestion rates and respiration rates are potentially subject to very large estimation errors. Given the variability intrinsic in the data, it is likely that community-level predictions based on this approach possess very little statistical power. For this reason it is most secure to focus measurement effort on the differences directly. Many characteristics measurable at the individual or population level are suitable for this purpose, including natality, individual weight gain, population growth rate, and threshold food concentrations. Some of these properties may vary with individual size but others will not. Direct measurements of threshold food concentrations, for example, suggest that the levels are taxonspecific and not necessarily dependent on individual size.

\section{References}

Alldredge, A. L. 1984. The quantitative significance of gelatinous zooplankton as pelagic consumers, p. 407-433. In Flows of energy and materials in marine cosystems. NATO Conf. Ser. 4, Mar. Sci. V. 13. Plenum.

Beadle, L. C. 1981. The inland lakes of tropical Africa, 2 nd ed. Longman.

Beers, J. R., and G. L. Stewart. 1971. Micro-zooplankton in the plankton communities of the upper waters of the castern tropical Pacific. DeepSea Res. 18: 861-883.

BIRD, D. F., AND J. KALFF. 1986. Bacterial grazing by planktonic lake algae. Science 231: 493-495.

- , AND Y. T. PraIRIE. 1985. Practical guidelines for the use of zooplankton length-weight regression equations. J. Plankton Res. 7: 955-960.

Brooks, J. L. 1950. Speciation in ancient lakes. Rev. Biol. 25: 30-60, 131-176.

—, AND S. I. Dodson. 1965. Predation, body size, and the composition of the plankton. Science 150: 28-35.

Carpenter, S. R., AND J. F. Kitchell. 1984. Plankton community structure and limnetic primary production. Am. Nat. 124: 159-172.

CONDREY, R. E. 1982. Ingestion-limited growth: The case for Blackman kinetics. Can. J. Fish. Aquat. Sci. 39: 1585-1595.

- , AND D. A. Fuller. 1985. Testing equations of ingestion-limited growth. Ergeb. Limnol. 21: 257-267.

Conover, R. J. 1979. Secondary production as an ecological phenomenon, p. 50-86. In S. van der Spoel and A. C. Pierrot-Bults [eds.], Zoogeography and diversity of plankton. Halsted.

$\longrightarrow$, AND M. HunTLEy. 1980. General rules of grazing in pelagic ecosystems, p. 461-485. In Primary production in the sea. Brookhaven Symp. Biol. 31. Plenum.
Downing, J. A., AND F. H. Rigler. 1984. A manual on methods for the assessment of secondary productivity in fresh waters, 2nd ed. Blackwell.

Durbin, E. G., A. G. Durbin, T. J. SMAYdA, AND P. G. VERITY, 1983. Food limitation of production by adult Acartia tonsa in Narragansett Bay, Rhode Island. Limnol. Oceanogr. 28: 1199-1213.

Farlow, J. O. 1976. A consideration of the trophic dynamics of a late Cretaceous large-dinosaur community (Oldman Formation). Ecology 57: 841857.

FERnANDo, C. H. 1980a. The freshwater zooplankton of Sri Lanka with a discussion of tropical freshwater zooplankton composition. Int. Rev. Gesamten Hydrobiol. 65: 85-125.

- $1980 \mathrm{~b}$. The species and size composition of tropical freshwater zooplankton with special reference to the oriental region (Southeast Asia). Int. Rev. Gesamten Hydrobiol. 65: 411-426.

FINNEY, D. I. 1941. On the distribution of a variate whose logarithm is normally distributed. J. R. Stat. Soc. Lond. Ser. B 7: 155-161.

FreY, D. G. 1982. Questions concerning cosmopolitanism in Cladocera. Arch. Hydrobiol. 93: 484502.

Galbraith, M. G., JR. 1967. Size-selective predation on Daphnia by rainbow trout and yellow perch. Trans. Am. Fish. Soc. 96: 1-10.

Gımble, J. C. 1978. Copepod grazing during a declining spring phytoplankton bloom in the northern North Sea. Mar. Biol. 49: 303-315.

Gerritsen, J., AND J.-I. Kou. 1985. Food limitation and body size. Ergeb. Limnol. 21: 173-184.

GLIwICZ, Z. M. 1975. Effect of zooplankton grazing on photosynthetic activity and composition of phytoplankton. Int. Ver. Theor. Angew. Limnol. Verh. 19: 1490-1497.

- 1985. Predation or food limitation: An ultimate reason for extinction of planktonic cladoceran species. Ergeb. Limnol. 21: 419-430.

GREEN, J. 1972. Latitudinal variation in associations of planktonic Rotifera. J. Zool. Lond. 167: 31-39.

Hairston, N. G., JR., AND W. R. MUNNS, JR. 1984. The timing of diapause as an evolutionary stable strategy. Am. Nat. 123: 733-751.

Hall, D. J., C. W. Burns, AND P. H. Crowley. 1976. The size-efficiency hypothesis and the size structure of zooplankton communities. Annu. Rev. Ecol. Syst. 7: 177-208.

Harbison, G. R., V. L. McAlister, AND R. W. GilMER. 1986. The response of the salp, Pegea confoederata, to high levels of particulate matcrial: Starvation in the midst of plenty. Limnol. Oceanogr. 31: 371-382.

HARris, R. P., AND G.-A. PAfFenhöFer. 1976. The effect of food concentration on cumulative ingestion and growth efficiency of two small marine planktonic copepods. J. Mar. Biol. Assoc. U.K. 56: $875-888$.

HARRISON, W. G. 1980. Nutrient regeneration and primary production in the sea, p. 433-460. In Primary productivity in the sea. Brookhaven Symp. Biol. 31. Plenum.

HeCKy, R. E., AND H. J. KLING. 1981. The phyto- 
plankton and protozooplankton of the euphotic zone of Lakc Tanganyika: Species composition, biomass, chlorophyll content, and spatio-temporal distribution. Limnol. Oceanogr. 26: 548-564.

Heinle, D. R. 1981. Zooplankton, p. 85-145. In F. J. Vernberg and W. B. Vernberg [eds.], Functional adaptations of marine organisms. Academic.

HRBÁČEK, J. 1962. Species composition and the amount of the zooplankton in relation to the fish stock. Rozpr. Cesk. Akad. Ved Rada Mat. Prir. Ved 10: $116 \mathrm{p}$.

- _ - M. DVořákova, M. KoŔíneK, AND L. ProcházKová. 1961. Demonstration of the effect of fish stock on the species composition of zooplankton and the intensity of metabolism of the whole plankton association. Int. Ver. Theor. Angew. Limnol. Vcrh. 14: 192-195.

HUNTLEY, M. 1985. A method for estimating foodlimitation and potential production of zooplankton communities. Ergeb. Limnol. 21: 41-55.

- - AND C. M. BoyD. 1984. Food-limited growth of marine zooplankton. Am. Nat. 124: 455-478.

Hutchinson, G. E. 1961. The paradox of the plankton. Am. Nat. 95: 137-145.

-__ 1967. A treatise on limnology. V. 2. Wilcy.

INFANTE, A., AND S. E. B. Abella. 1985. Inhibition of Daphnia by Oscillatoria in Lake Washington. Limnol. Oceanogr. 30: 1046-1052.

JENKINS, W. J. 1982. Oxygen utilization rates in North Atlantic subtropical gyre and primary production in oligotrophic systems. Nature 300: 246-248.

JoHnson, N. L., AND F. C. LeONE. 1964. Statistics and experimental design. V. 1. Wiley.

Knoechel, R., AND L. B. Holtby. 1986. Construction and validation of a body-length-based model for the prediction of cladoccran community filtering rates. Limnol. Oceanogr. 31: 1-16.

Koch, A. L. 1966. The logarithm in biology. 1. Mechanisms generating the log-normal distribution. J. Theor. Biol. 12: 276-290.

Kozhov, M. M. 1963. Lake Baikal and its life. Junk.

LAMPERT, W. 1977. Studies on the carbon balance of Daphnia pulex de Geer as related to environmental conditions. 4. Determination of the "threshold" concentration as a factor controlling the abundance of zooplankton species. Arch. Hydrobiol. Suppl. 48 , p. $361-368$.

- _._- [ED.]. 1985. Food limitation and the structure of zooplankton communities. Ergeb. Limnol. 21: 497 p.

, AND P. MUCK. 1985. Multiple aspects of food limitation in zooplankton communities: The Daphnia-Eudiaptomus example. Ergeb. Limnol. 21: $311-322$.

-_- AND U. SCHOBER. 1980. The importance of "threshold" food concentrations. Am. Soc. Limnol. Oceanogr. Spec. Symp. 3: 264-267. New England.

LANDRY, M. R., AND R. P. HASSETT. 1982. Estimating the grazing impact of marine micro-zooplankton. Mar. Biol. 67: 283-288.

_— AND - 1985. Time scales in behavioral, biochemical, and energetic adaptations to foodlimiting conditions by a marine copepod. Ergeb. Limnol. 21: 209-221.
LAw/S, E. A., AND OTHERs. 1984 High phytoplankton growth and production rates in oligotrophic Hawaiian coastal waters. Limnol. Oceanogr. 29: 1161-1169.

Lehman, J. T., AND C. D. SANDGRen. 1985. Speciesspecific rates of growth and grazing loss among freshwater algae. Limnol. Oceanogr. 30: 34-46.

LeSeur, B. W. 1960. The life history of Daphnia pulex spp. pulicoides. Proc. Mont. Acad. Sci. 19: $80-83$.

LEwIS, W. M., JR. 1974. Primary production in the plankton community of a tropical lake. Ecol. Monogr. 44: 377-409.

LYNCH, M. 1977. Fitness and optimal body size in zooplankton populations. Ecology 58: 763-774.

- 1979. Predation, competition, and zooplankton community structure: An experimental study. Limnol. Oceanogr. 24: 253-272.

— AND J. ShapIRo. 1981. Predation, enrichment, and phytoplankton community structure. Limnol. Oceanogr. 26: 86-102.

$\longrightarrow$ - L. J. WEIDER, AND W. LAMPERT. 1986. Measurement of the carbon balance in Daphnia. Limnol. Oceanogr. 31: 17-33.

MCGowan, J. A., AND P. W. WAlker. 1979. Structure in the copepod community of the North Pacific central gyre. Ecol. Monogr. 49: 195-226.

MANN, K. H. 1988. Production and use of detritus in various freshwatcr, cstuarinc, and coastal marine ecosystems. Limnol. Oceanogr. 32: 910-930.

MAY, R. M. 1981. Theoretical ecology, 2nd ed. Sinauer.

MAYZAUD, P., AND O. MAYZAUd. 1985. The influence of food limitation on the nutritional adaptation of marine zooplankton. Ergeb. Limnol. 21: 223-233.

Meise, C. J., W. R. MunNs, JR., AND N. G. Hairston, JR. 1985. An analysis of the feeding behavior of Daphnia pulex. Limnol. Oceanogr. 30: 862-870.

Muck, P., AND W. LAMPERT. 1984. An experimental study on the importance of food conditions for the relative abundance of calanoid copepods and cladocerans. 1. Comparative feeding studies with Eudiaptomus gracilis and Daphnia longispina. Arch. Hydrobiol. Suppl. 66, p. 157-179.

Mullin, M. M., AND E. R. Brooks. 1970. The effect of concentration of food on body weight, cumulative ingestion, and rate of growth of the marine copepod Calanus helgolandicus. Limnol. Oceanogr. 15: 748-755.

NiLSSEN, J. P. 1978. On the evolution of life histories of limnetic cyclopoid copcpods. Mem. Ist. Ital. Idrobiol. 36: 193-214.

- 1980. When and how to reproduce: A dilemma for limnetic cyclopoid copepods. Am. Soc. Limnol. Oceanogr. Spec. Symp. 3: 4 18-426. New England.

O'BRIEN, W. J. 1979. The predator-prey interaction of planktivorous fish and zooplankton. Am. Sci. 67: 572-581.

Orcutt, J. D., Jr., AND K. G. Porter. 1983. Diel vertical migration by zooplankton: Constant and fluctuating temperature effects on life history parameters of Daphnia. Limnol. Oceanogr. 28: 720730.

Patalas, K., AND A. Salki. 1984. Effects of im- 
poundment and diversion on the crustacean plankton of southern Indian Lake. Can. J. Fish. Aquat. Sci. 41: 613-637.

PeJler, B. 1977. General problems on rotifer taxonomy and global distribution. Ergeb. Limnol. 8: 212-220.

Peters, R. H. 1983. The ecological implications of body size. Cambridge.

—_, AND J. A. DowNING. 1984. Empirical analysis of zooplankton filtering and fecding rates. Limnol. Oceanogr. 29: 763-784.

PIYASIRI, S. 1985. Methodological aspects of defining food dependence and food thresholds in fresh-water calanoids. Ergeb. Limnol. 21: 277-284.

POMEROY, L. R. 1979. Secondary production mechanisms of continental shelf communities, p. 163186. In R. J. Livingston [ed.], Ecological processes in coastal and marine ecosystems. Plenum.

Richman, S., AND S. I. DoDson. 1983. The effect of food quality on feeding and respiration by Daphnia and Diaptomus. Limnol. Oceanogr. 28: 948956.

RigLER, F. H. 1975. Nutrient kinetics and the new typology. Int. Ver. Theor. Angew. Limnol. Verh. 19: $197-210$.

Robinson, W. R., R. H. Peters, AND J. Zimmerman. 1983. The effects of body size and tempcrature on metabolic rate of organisms. Can. J. Zool. 61: 281-288.

ROMANOVSKY, Y. E. 1984. Individual growth rate as a measure of competitive advantages in cladoceran crustaceans. Int. Rev. Gesamten Hydrobiol. 69: 613-632.

- 1985. Food limitation and life-history strategies in cladoceran crustaceans. Ergeb. Limnol. 21: 363-372.

Ryther, J. H. 1969. Photosynthesis and fish production in the sea. Science 166: 72-76.

SCHIEMER, F, 1985. Bioenergetic niche differentiation of aquatic invertcbrates. Int. Ver. Theor. Angew. Limnol. Verh. 22: 3014-3018.

Schulenberger, E., And J. L. Reid. 1981. The Pacific shallow oxygen maximum, deep chlorophyll maximum, and primary productivity, reconsidered. Decp-Sea Res. 28: 901-919.

Sheldon, R. W., A. Prakash, and W. H. Sutcliffe, JR. 1972. The size distribution of particles in the occan. Limnol. Oceanogr. 17: 327-340.

Silvert, W., AND T. Platt. 1980. Dynamic energyflow model of the particle-size distribution in pelagic ccosystems. Am. Soc. Limnol. Oceanogr. Spcc. Symp. 3: 754-763. New England.

SOROKIN, Y. I. 1981. Microheterotrophic organisms in marine ecosystems, p. 293-342. In A. R. Longhurst [ed.], Analysis of marine ecosystems. Academic.

SPRUGEL, D. G. 1983. Correcting for hias in log-transformed allometric equations. Ecology 64: 209-210.

Sprules, W. G., AND R. Knoechel. 1984. Lake ecosystem dynamics based on functional representations of trophic components, p. 383-403. In Trophic interactions within aquatic ecosystems. Am. Assoc. Adv. Sci. Select. Symp. 85. Westvicw. Steele, J. H. 1978. Some comments on plankton patches, p. 1-20. In J. H. Steelc [ed.], Spatial pattern in plankton communities. Plenum.

— AND B. W. Frost. 1977. The structure of plankton communities. Phil. Trans. R. Soc. Lond. Ser. B 280: 485-534.

-, AND J. C. GAMBLE. 1982. Predator control in - enclosures, p. 227-237. In G. D. Grice and M. R. Reeve [eds.], Marine mesocosms: Biological and chemical research in experimental ecosystems. Springer.

Stemberger, R. S., AND J. J. Gilbert. 1985. Body size, food concentration and population growth in planktonic rotifers. Ecology 66: 1151-1159.

Strickler, J, R., AND S. TwOMBLy. 1975. Reynolds number, diapause and predatory copepods. Int. Ver. Theor. Angew. Limnol. Verh. 19: 2943-2950.

TiLman, D. 1980. Resources: A graphical-mechanistic approach to competition and predation. Am. Nat. 116: 362-393.

-1982. Resource competition and community structure. Princeton.

TRANTER, D. J. 1976. Herbivore production, p. 186224. In D. H. Cushing and J. J. Walsh [eds.], The ecology of the seas. Blackwell.

Twombly, S. 1983. Seasonal and short term fluctuations in zooplankton abundance in tropical Lake Malawi. Limnol. Oceanogr. 28: 1214-1224.

Valentine, J. W., AND F. J. Ayala. 1978. Adaptive strategies in the sea, p. 323-345. In B. Battaglia and J. A. Beardmore [eds.], Marine organisms. Plenum.

VIDAL, J. 1980. Physioecology of zooplankton. 1. Effects of phytoplankton concentration, temperature, and body size on the growth rate of Calanus pacificus and Pseudocalanus sp. Mar. Biol. 56: 111134.

VinoGRADOV, M. E. 1981. Ecosystems of equatorial upwellings, p. 69-93. In A. R. Longhurst [ed.], Analysis of marine ecosystems. Academic.

Wells, L. 1970. Effects of alewife predation on zooplankton populations in Lake Michigan. Limnol. Oceanogr. 15: 556-565.

Wetzel, R. G. 1983. Limnology, 2nd ed. Saunders.

WILlIAMS, R. 1984. An overview of secondary production in pelagic ecosystems, p. 361-405. In Flows of energy and materials in marine ecosystems. NATO Conf. Ser. 4, Mar. Sci. V. 13. Plenum.

Williamson, C. E., N. M. Butler, and L. Forcina. 1985. Food limitation in naupliar and adult Diaptomus pallidus. Limnol. Oceanogr. 30: 1283-1290.

ZareT, T. M. 1969. Predation-balanced polymorphism of Ceriodaphnia cornuta Sars. Limnol. Occanogr. 14: 301-303.

- 1972 . Predators, invisible prey, and the nature of polymorphism in the Cladocera (Class Crustacea). Limnol. Oceanogr. 17: 171-184.

1975. Strategies for existence of zooplankton prey in homogencous environments. Int. Ver. Theor. Angew. Limnol. Verh. 19: 1484-1489.

- 1980. Predation and freshwater communities. Yale.

$\longrightarrow$ - AND J. S. SUFFERN. 1976. Vertical migration in zooplankton as a predator avoidance mechanism. Limnol. Oceanogr. 21: 804-813. 